\title{
O estágio supervisionado no Ensino Fundamental do curso de Licenciatura em Física: contribuições para a formação docente na perspectiva dos estagiários
}

\author{
Mauro Parnaiba Duarte ${ }^{1}$ (D) \& Heydson Henrique Brito da Silva ${ }^{2}$ (D)
}

(1) Universidade Federal da Paraíba - Campus I, Departamento de Física, Programa de Pós-Graduação em Física, Cidade Universitária, João Pessoa 58051-900, Paraíba, Brasil.

E-mail: mauropduarte12@gmail.com

(2) Universidade Federal de Campina Grande, Centro de Formação de Professores, Unidade Acadêmica de Ciências Exatas e da Natureza, Rua Sérgio Moreira de Figueiredo, Casas Populares, Cajazeiras 58900000, Paraíba, Brasil. E-mail: heydson.brito@ufcg.edu.br

Duarte M.P. \& Silva H.H.B. (2020) O estágio supervisionado no Ensino Fundamental do curso de Licenciatura em Física: contribuições para a formação docente na perspectiva dos estagiários. Pesquisa e Ensino em Ciências Exatas e da Natureza, 4: e1405. http://dx.doi.org/10.29215/pecen.v4i0.1405

Editor acadêmico: Diego Marceli Rocha. Recebido: 25 julho 2019. Aceito: 04 junho 2020. Publicado: 05 junho 2020.

Resumo: Neste trabalho buscamos investigar algumas contribuições e desafios do componente curricular Estágio Supervisionado I para a formação docente, sob a perspectiva dos estagiários, no curso de Licenciatura em Física do Centro de Formação de Professores (CFP) da Universidade Federal de Campina Grande (UFCG). Trata-se de um estudo de caso, onde aplicamos um questionário aberto a 25 estudantes que já realizaram a disciplina de Estágio Supervisionado I (o qual aborda o ensino de ciências no Nível Fundamental) no Curso de Licenciatura em Física do CFP. Estes dados foram analisados de modo qualitativo e esquematizados como propõe Bardin (1977, 2011). Constatamos que os mesmos relatam inúmeros contratempos referentes ao processo burocrático do estágio, como também contribuições positivas em relação à prática na sala de aula, no que diz respeito à melhora do desempenho acadêmico dos estagiários ao longo do curso e na sua identificação como futuros professores de Física. Além disso, os estagiários evidenciam as experiências pessoais vividas, no sentido de contribuir significativamente para sua formação, não só como pessoa, ao interagir com pessoas de diferentes contextos, mas também profissional, ao permitir o contato e reflexão dos problemas enfrentados na sala de aula nesse nível de ensino.

Palavras chave: Ensino de Física, Estágio supervisionado, Formação docente, Ensino Fundamental.

The Supervised Internship in Elementary Schoolof Physics course: contributions to teaching training in the perspective of trainers

Abstract: In this work we seek to investigate some contributions and challenges of the curricular component named Estágio Supervisionado I for teacher training, from the trainees' perspective, in the Physics course of Centro de Formação de Professores (CFP) of Universidade Federal de Campina Grande (UFCG). This is a case study, where we applied an open questionnaireto 25 students who have already completed the Supervised Internship I (which addresses science teaching at the Elementary School) in the CFP Physics Degree Course. These data were analyzed qualitatively and outlined as proposed Bardin (1977, 2011). We found that they report numerous setbacks regarding the bureaucratic process of the internship, as well as positive contributions in relation to the practice in the classroom, with regard to improving the academic performance of the interns throughout the course and in their identification as future teachers of Physics. In addition, the interns show their personal experiences, in the sense of contributing significantly to their training, not only as a person, when interacting with people from different contexts, but also as a professional, allowing contact and reflection of the problems faced in the classroom in this level of education.

Key words: Teaching of Physics, Supervised internship, Teaching formation, Elementary School. 


\section{Introdução}

O estágio supervisionado possibilita uma melhor compreensão de como é dinâmico e complexo o contexto escolar, principalmente na Educação Básica (se tratando de crianças e adolescentes), constituindo assim, um importante aspecto para a formação, não apenas acadêmica e da nossa prática pedagógica, mas também como pessoa, ao se relacionar com pessoas de diferentes contextos sociais, culturais e intelectuais.

Tal componente curricular tem como finalidade desenvolver habilidades práticas do que foi aprendido na teoria dos cursos de licenciatura (Silva \& Miranda 2008; Pimenta \& Lima 2012; Pimenta 2013). Já Carvalho (2009) ressalta o estágio como sendo um momento que possibilita a construção de um estilo próprio, fundamentado nos diversos saberes que compõem a nossa formação profissional, unificada a valores éticos, sociais, humanos e estéticos calcados na nossa história pessoal.

No entanto, o estágio é comumente visto apenas como a "parte prática” dos cursos de formação docente, fortalecendo uma visão desconexa e fragmentada das disciplinas dos cursos formadores, como afirma Pimenta e Lima:

[...] a atividade de estágio fica reduzida à hora da prática, ao "como fazer”, às técnicas a serem empregadas em sala de aula, ao desenvolvimento de habilidades específicas do manejo de classe, ao preenchimento de fichas de observação, diagramas, fluxogramas (Pimenta \& Lima 2012: 37).

Essa concepção acaba restringindo o estágio a um mero período de instrumentalização, marcado por inúmeras técnicas a serem aplicadas no contexto da sala de aula, ou a um simples cumprimento de horas formais exigidas pela legislação. Barreiro \& Gebran (2016) também reflete neste sentido, ao afirmar que o estágio passa a ser entendido como uma prática instrumentalizada, organizada de maneira burocrática, com o preenchimento de fichas e com a valorização de atividades que envolvem observações, participação e regência, desprovidas de uma meta investigativa e reflexiva.

Portanto, essa instrumentalização do estágio torna-o ineficiente no seu verdadeiro papel no desenvolvimento do discente como profissional, levando-o a um status de simples observador de aulas dos professores para imitá-los como modelos, sem ser necessário antes se fazer "uma análise crítica fundamentada teoricamente e legitimamente na realidade social em que o ensino se processa” (Pimenta \& Lima 2012: 36).

O estágio deve então ser compreendido como um meio para a investigação sobre a realidade da prática docente nas salas de aula, para que através de uma reflexão consciente e fundamentada, seja possível se fazer uma investida significativa sobre essa realidade na perspectiva de mudança. Assim, o estágio deixa de ser entendido como uma "parte prática" instrumentalizada e passa a ser compreendido como teórico e prático, superando esse distanciamento entre a teoria e a prática, bem como entre a universidade e a escola.

Para Silva \& Miranda (2008), o processo reflexivo não ocorre de forma linear, pois envolve a análise, a problematização, assim como o enfrentamento de dúvidas e incertezas. Segundo os autores "trata-se de um movimento dialético do conhecimento, que compreende o momento da ação, da reflexão, e da ação refletida como prática modificada” (Silva \& Miranda 2008: 16).

Neste sentido, Barreiro e Gebran enfatizam que:

[...] o estágio coloca-se como teórico-prático e não como teórico ou prático, devendo possibilitar, aos estagiários, melhor compreensão das práticas institucionais e das ações praticadas pelos profissionais, como maneira de preparar os futuros professores (Barreiro \& Gebran 2006: 28).

Desse modo, o estágio, por permitir vivenciar situações em que os discentes se colocam na posição de docentes, possibilita que estes reflitam sobre a prática docente, a partir dela, como um ser integrante, e assim, atuem nela como um profissional reflexivo, de forma a construir uma postura transformadora dessa realidade. 
No âmbito do Centro de Formação de Professores (CFP) da Universidade Federal de Campina Grande (UFCG), localizado na cidade de Cajazeiras-PB, o estágio supervisionado é uma etapa obrigatória no curso de Licenciatura em Física (como também em outros cursos) de caráter inerente à formação acadêmica profissional. Tem como objetivo fundamental construir condições intelectuais para que os estudantes possam produzir práticas pedagógicas, adequadamente apoiadas na fundamentação teórica e nas tendências atuais do Ensino da Física na Educação Básica que permeiam o Projeto Pedagógico do Curso, de acordo com o Art. $1^{\circ}$, da resolução Nº3/2013 que regulamenta o estágio supervisionado no âmbito do Curso de Física do CFP/UFCG.

Um dos objetivos propostos para o Estágio Supervisionado I no curso de Física do CFP, segundo o seu projeto político pedagógico, corresponde ao planejamento e execução de atividades de ensino de conteúdos da Física no Ensino Fundamental, pois é neste nível de ensino em que os estudantes terão o primeiro contato com os conhecimentos da Física na disciplina de Ciências.

Percebe-se, em geral, que pouco é discutido, de forma reflexiva, sobre as contribuições e os desafios que poderão ser encontrados pelos estagiários. Desafios estes que vão desde a relação entre estagiário e aluno (pois se trata de alunos jovens e adolescentes de diferentes contextos, em geral) até o processo de transposição didática, uma vez que o Ensino da Física no Ensino Fundamental implica em adaptações e mudanças metodológicas para uma melhor aprendizagem (Duarte 2005; Coutinho et al. 2014).

Neste trabalho buscamos responder a seguinte pergunta: Quais são as contribuições e os desafios do Estágio Supervisionado I para a formação dos discentes do curso de Física do CFP/UFCG sob a perspectiva dos estagiários? Pretendemos investigar aqui desde os processos burocráticos iniciais do estágio até alguns aspectos referente à sua prática em sala de aula, buscando observar a maneira como essas contribuições e desafios estão articulados com a realidade do sistema educacional estabelecido. Isto permitirá identificar se a atuação do estagiário segue trilhos que o permite tornar-se um profissional reflexivo, como discutido anteriormente. Tudo isto proporcionará subsídios teóricos que poderão servir para aqueles acadêmicos que irão cursar ou que já estão cursando o estágio supervisionado.

\section{Metodologia}

A pesquisa realizada é classificada, enquanto seus procedimentos técnicos, como um estudo de caso, na qual optamos por realizar uma abordagem qualitativa na análise dos dados. Segundo Prodanov \& Freitas (2013: 60) “o estudo de caso consiste em coletar e analisar informações sobre determinado indivíduo, uma família, um grupo ou uma comunidade, a fim de estudar aspectos variados de sua vida, de acordo com o assunto da pesquisa."

Procuramos estabelecer uma compreensão criteriosa dos dados, na qual buscamos um embasamento literário bem estruturado, que deu suporte teórico aprofundado sobre as dificuldades, acertos e desafios acerca do tema em questão. Como referenciais teóricos norteadores desta pesquisa temos Martins (2009), Pozo \& Crespo (2009), Pimenta \& Lima (2012), Silva \& Fajardo-Turbin (2012), Carvalho (2013), Pimenta (2013), Barreiro \& Gebran (2016) e Celestino (2016).

Os sujeitos da pesquisa consistem em estudantes de diversos períodos do Curso de Licenciatura em Física do CFP/UFCG. Como critério de inclusão para participação na pesquisa, foram considerados estudantes que já tinham cumprido o Estágio Supervisionado I, e como critério de exclusão, aqueles alunos que estão cursando ou que nunca cursaram o referido componente curricular.

Como instrumento de coleta de dados aplicamos um questionário aberto, contendo inicialmente perguntas descritivas sobre o participante, como o sexo, o período que está cursando (e o que deveria estar se estivesse no fluxo normal do curso), onde realizou o estágio e se já tinha experiência em docência. Na sequência, apresentamos ao sujeito os seguintes questionamentos acerca da sua experiência no estágio supervisionado: 
- Questão 1: Quais os aspectos no processo burocrático do estágio supervisionado você considera um empecilho? E de que maneira seria possível superá-los?

- Questão 2: De que forma você considera que o Estágio Supervisionado I favorece no seu desenvolvimento acadêmico no Curso de Física?

- Questão 3: Quais as dificuldades e as facilidades você destaca, durante todo o desenrolar do estágio de regência, considerando tudo que você estudou na teoria?

- Questão 4: Em quais aspectos você considera o Estágio Supervisionado I importante para a sua formação como docente?

- Questão 5: Quais as contestações e as considerações (ou contentamentos) você tem do Estágio Supervisionado I, em geral?

A justificativa para a aplicação de um questionário (e não a realização de entrevistas, por exemplo) se dá pelo fato de podermos atingir um número maior e significativo de sujeitos (Marconi \& Lakatos 2017). Outro motivo para a conveniência do uso do questionário é o fato de que o Curso de Licenciatura em Física do CFP/UFCG é realizado no turno da noite e engloba sujeitos de várias localidades, pois o campus é um polo regional de educação. Logo, ao fazer um breve levantamento inicial na coordenação do curso dos potenciais sujeitos da pesquisa, foi possível agendar encontros individuais e em grupo para a aplicação presencial do questionário. Enquanto às perguntas acerca da experiência dos sujeitos no estágio (questões 1 a 5), sua elaboração foi motivada pelas diversas discussões apresentadas nas referências norteadoras anteriormente citadas.

Os sujeitos que atenderam os critérios de inclusão e exclusão supracitados totalizaram 25 (vinte e cinco) estudantes, dos quais 10 (dez) eram do sexo feminino e 15 (quinze) do sexo masculino. Esta caracterização evidenciou, de certo modo, a ascensão nos últimos tempos da participação de mulheres na área da Física (Leta 2003; Agrello \& Garg 2009). Verificamos que os participantes estavam cursando entre o $6^{\circ}$ e o $10^{\circ}$ período, sendo quase todos não "blocados" (ou seja, que não cumpriram as disciplinas da grade curricular do curso nos períodos corretos) e alguns com matrículas novas. Assim, neste cenário, temos estudantes que estavam cursando disciplinas do $3^{\circ}$ período e estudantes que já deveriam estar formados.

Destacamos que cerca de 1/3 (um terço) aproximadamente dos participantes (9 no total) possuíam alguma outra experiência como professor, seja por ter ministrado aula por algum tempo, como professor substituto, ou ter participado do PIBID (Programa Institucional de Bolsas de Iniciação à Docência) da CAPES que permite vivenciar tal experiência, além daqueles que já trabalhavam como professor na educação infantil. Para estes que já lecionavam, podemos ressaltar o que afirma Pimenta \& Lima (2012), que essa etapa poderia se mostrar como um momento de formação continuada, em que estes poderiam refletir sobre a sua própria prática pedagógica. Assim, o ato de aprender continuamente, "é mais do que uma ação a ser executada, é um valor a ser construído e cultivado ao longo de nossas vidas” (Brasil 2012: 27).

Como método de análise de dados, seguimos o que apresenta Bardin (1977), intitulado "Análise de conteúdos". Nesta proposta, temos três diferentes fases de análise de conteúdo: a préanálise, a exploração do material e o tratamento dos resultados, inferência e interpretação (Bardin 1977, 2011).

A pré-análise é a primeira fase da pesquisa. É a fase de organização propriamente dita. "Corresponde a um período de intuições, mas tem por objetivo tornar operacionais e sistematizar as ideias iniciais, de maneira a conduzir a um esquema preciso do desenvolvimento das operações sucessivas" (Bardin 2011: 125). Na fase de exploração do material, ocorre a aplicação sistemática, manual ou informatizada, das decisões tomadas na pré-análise. Consiste, essencialmente, em operações de codificação, decomposição ou enumeração, em função das regras previamente estabelecidas. Por fim, na fase do tratamento dos resultados, inferência e interpretação, ocorrem as análises para que os dados sejam significativos e válidos. "Operações estatísticas simples (percentagens) permitem estabelecer quadros de resultados, diagramas, figuras e modelos, os quais condensam e põem em relevo as informações fornecidas pela análise (Bardin 2011: 131).” 
Por fim, como parte deste trabalho envolve contato direto com seres humanos, o procedimento de coleta de dados foi apreciado pelo Comitê de Ética do CFP/UFCG. Seguimos as exigências éticas e científicas das Resoluções 466/2012 e 510/2016 do Conselho Nacional de Saúde (CNS), assegurando aos participantes sigilo e privacidade das informações que foram coletadas, firmando o compromisso de utilização dessas informações somente para fins científicos e acadêmicos.

\section{Resultados e Discussão}

$\mathrm{Na}$ análise dos questionários aplicados, buscamos retratar os dados obtidos de modo quantitativo, e interpretá-los qualitativamente. Para Minayo \& Sanches (1993: 247), "uma pesquisa, por ser quantitativa, não se torna "objetiva" e "melhor", ainda que prenda à manipulação sofisticada de instrumentos de análise, caso deforme ou desconheça aspectos importantes dos fenômenos ou processos sociais estudados." Da mesma forma, "uma abordagem qualitativa em si não garante a compreensão em profundidade. "Portanto, tal análise qualitativa foi realizada através de uma correlação entre os dados apresentados e os referenciais teóricos que fundamentaram esse trabalho.

Na questão 1 que compõe o referido questionário, buscamos investigar as perspectivas dos estudantes em relação aos processos burocráticos do estágio, intrínsecos ao sistema institucional, sendo exigido para o cumprimento do estágio. Os resultados estão ilustrados no gráfico da Figura 1.

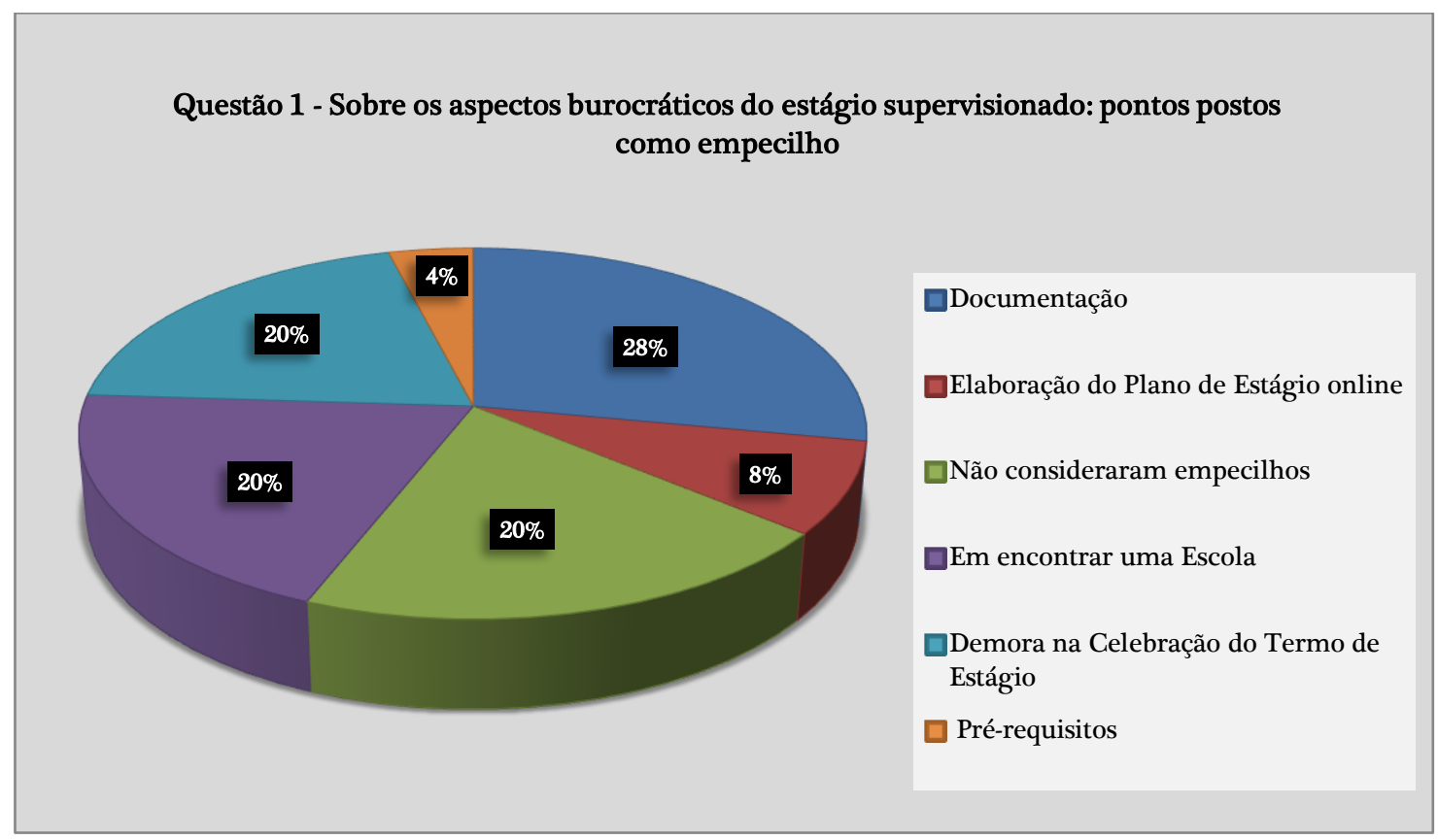

Figura 1. Aspectos burocráticos do estágio supervisionado: pontos postos como empecilho.

Podemos notar pelos dados obtidos, que as maiores queixas são quanto à documentação (28\%), à demora para a celebração do termo de compromisso (20\%), e em encontrar uma escola para a realização do estágio (20\%). As queixas quanto à documentação estão no sentido de serem exigidos muitos papéis e assinaturas, causando até certo incômodo aos supervisores e à direção da escola onde o discente vai estagiar (estes chegam a cogitar como solução a possibilidade de diminuir essa documentação). Exibimos aqui alguns comentários de participantes que enfatizam estes resultados:

[...] o recolhimento das assinaturas, que acaba atrasando as atividades do estágio, é algo chato." (estudante do $8^{\circ}$ período)

“Um empecilho é a documentação exigida, é muito papel, muitas vezes a direção da escola demostrava certo incomodo. Uma forma de superar isso, seria apossibilidade de diminuindo esses documentos." (estudante do $6^{\circ}$ período) 
“O meu maior empecilho foi na elaboração do plano de estágio online, é pouco tempo para elaborá-lo. Seria interessante ter um referencial/modelo para ajudar nessa etapa." (estudante do $6^{\circ}$ período)

"O maior empecilho é encontra a escola para realizar o estágio pois depende de vários fatores: a aceitação da escola, a ausência de professores da área, disponibilidade de horário; encaixamento do horário do estagiário e das aulas da escola. Não teria uma solução certa pois são fatores externos." (estudante do $\mathbf{8}^{\mathbf{0}}$ período)

"[...] muitas escolas não aceitam estagiários(as). poderia solucionar isso "diminuindo" a distância entre a escola e a universidade." (estudante do $10^{\circ}$ período)

"[...] a busca pela escola é muita das vezes cansativa física e emocionalmente, e a forma como os estagiários são tratados."(estudante do $8^{\circ}$ período)

"Um empecilho está na demora na aprovação dos termos de estágio por parte da direção, que acaba provocando um atraso nas atividades do estágio. Uma solução seria uma maior agilidade por parte dos responsáveis por essa demanda, os meus termos já foram até perdidos uma vez." (estudante do $\mathbf{8}^{\circ}$ período)

Quanto à demora na celebração do termo (20\%), os discentes ressaltaram que isso acaba atrasando as atividades de estágio e colocam como solução para isto uma maior agilidade e organização por parte da direção (relataram até casos de perda de papéis). $O$ outro aspecto que aparece em destaque remete à dificuldade em encontrar uma escola para a realização do estágio $(20 \%)$, pois os discentes ressaltam que muitas escolas (incluindo os professores) não aceitam estagiários, tornando a busca cansativa, tanto fisicamente como emocionalmente. Do ponto de vista dos estudantes, uma aproximação da universidade com a escola seria uma possível solução para isso, ou ao menos ajudaria. Destacam-se também aqueles que não consideraram ter encontrado empecilhos nessa etapa (20\%).

Em menor porcentagem se apresentam as respostas com relação à elaboração do plano de estágio do controle acadêmico online da universidade (8\%) e os pré-requisitos do estágio (4\%). Sobre a elaboração do plano de estágio online, os estagiários ressaltaram ter encontrado dificuldades na elaboração, bem como o fato de ser um curto tempo para elaborá-lo. Para tanto, os mesmos colocaram como uma possível solução um referencial/modelo para ajudar o estudante nessa etapa. Essa dificuldade na elaboração do plano de estágio online, ao nosso ver, é devido ao fato de ser a primeira vez que o estagiário está cursando esse componente curricular.

Na questão 2 buscamos investigar, na perspectiva dos estudantes, de que modo o Estágio Supervisionado I favorece no desenvolvimento dos mesmos ao longo do curso, já que o estágio aparentemente tem sido reduzido simplesmente a "hora da prática", como citamos anteriormente em Pimenta \& Lima (2012), sem nenhuma conexão com os outros componentes curriculares do curso. Organizamos os dados obtidos nas respostas em quatro categorias, apresentadas na Figura 2. De um modo geral, podemos observar nos resultados que o Estágio Supervisionado I tem contribuído de forma significativa para o desenvolvimento dos estagiários ao longo do curso de Física do CFP/UFCG, se caracterizando como uma fonte pertinente para a construção de conhecimentos didáticos para a prática docente e também sobre o ensino da Física.

Dentre os pontos elencados, o que mais se destaca com $48 \%$ do percentual total, está relacionado ao aprimoramento da desenvoltura destes estagiários nas disciplinas de caráter pedagógico, tanto na perspectiva de produção acadêmica (na apresentação de trabalhos, na escrita de texto, na produção de relatórios etc.) como também nas discussões teóricas relacionadas ao ensino. Os estagiários consideram que essa etapa é uma oportunidade para melhorar a sua postura como docente e para refletir sobre as suas práticas metodológicas, mediante as situações que exijam uma postura como educador durante o processo de formação no curso, conforme relatado pelos sujeitos participantes da pesquisa, a saber:

"Tenho a oportunidade de melhorar minha postura e de refletir sobre as minhas práticas, sobre o que devo fazer e o que não devo." (estudante do $6^{\circ}$ período) 
"[...] permitindo uma noção do que fazer e de como agir como educador no processo de formação." (estudante do $6^{\circ}$ período)

“....] favorecendo o meu desenvolvimento no curso, nas apresentações de seminários, apresentações de aulas, e até a participação em sala de aula melhorou mais."(estudante do $8^{\circ}$ período)

“...] é o momento oportuno do/a estudante exercer na prática os conhecimentos construídos na academia, e refletir sobre eles no processo de formação, tanto do aspecto pedagógico, como os específicos da Física." (estudante do $10^{\circ}$ período)

“.... foi possível promover discussóes dentro do curso que contemplasse as diferentes situações vivenciadas."(estudante do $6^{\circ}$ período)

"Proporcionou um momento de preparação para o exercício da profissão uma vez que podemos identificar problemas e propor soluçôes para estes problemas."(estudante do $8^{\circ}$ período)

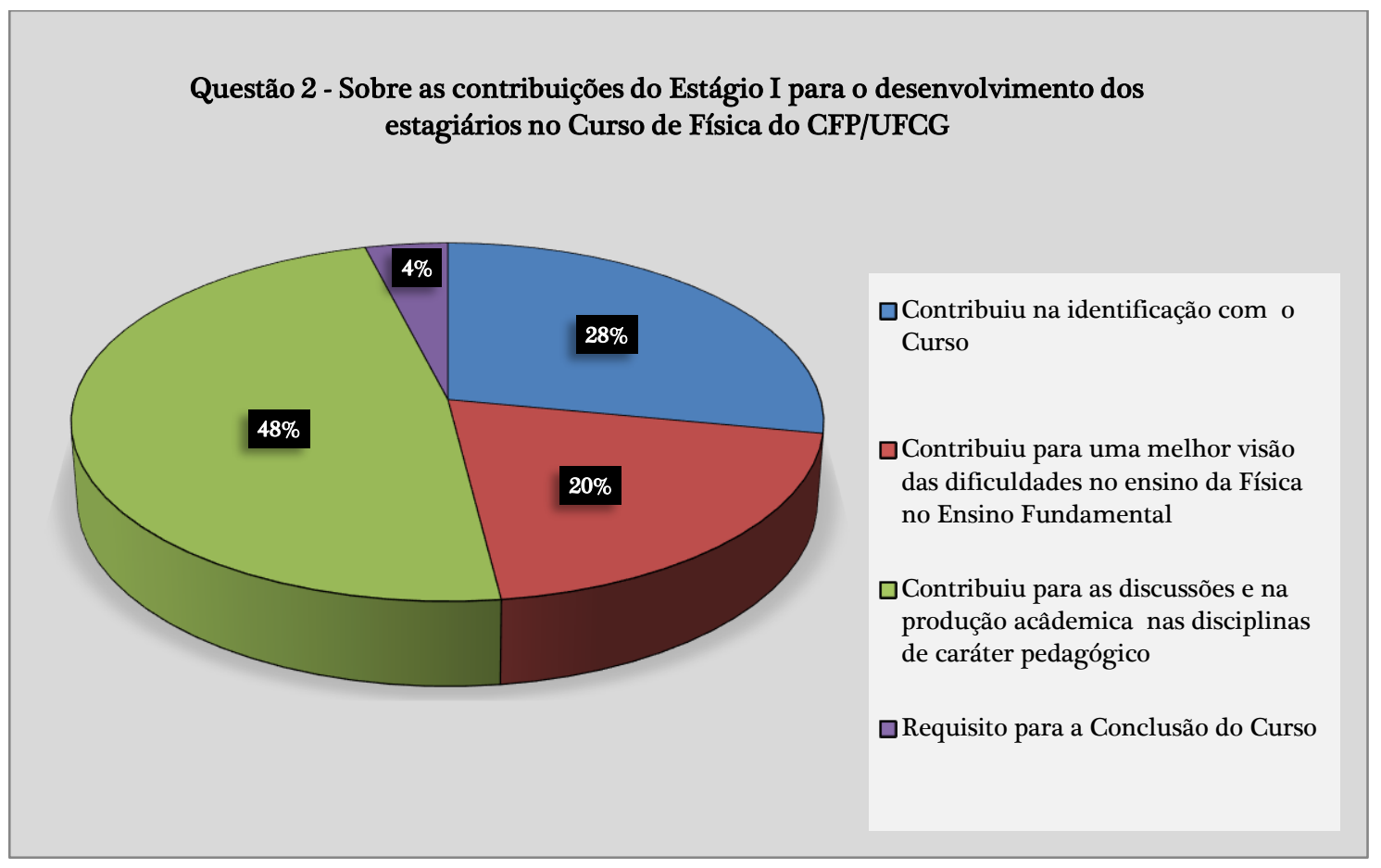

Figura 2. Contribuições do Estágio I para o desenvolvimento dos estagiários no Curso de Física.

Outro ponto posto em destaque mostra que o Estágio Supervisionado I contribuiu para a identificação com o curso (cerca de $28 \%$ das respostas). Sobre isso, destacamos que o estágio permitiu ao estudante vivenciar de fato a experiência como um professor de Física, se constituindo uma etapa decisiva para a escolha ou não por essa profissão, como vemos em alguns relatos:

"Contribuiu para confirmação na minha escolha como futuro profissional e também evidência a distância entre a teoria e a prática docente."(estudante do6 ${ }^{\circ}$ período)

"Passei a compreender o curso a partir de uma perspectiva diferente da que um dia já tive."(estudante do $8^{\circ}$ período)

“...] ajuda a saber se realmente é a carreira que quero pra mim.” (estudante do $8^{\circ}$ período)

“...] foi através dele que aumentou o interesse e o desejo de seguir na carreira docente, mesmo diante dos inúmeros desafios que a carreira docente oferece diante a realidade da educação brasileira atual." (estudante do $10^{\circ}$ período) 
Entretanto, vale ressaltar que essa identificação como futuro professor de Física não é constituída somente "à revelia dos sinais provenientes desses momentos", pois, há também os sinais implícitos que provêm "da longa e precedente história familiar e escolar do futuro professor de física, ou seja, dos anos de convívio com seus pais, familiares, colegas e professores da educação básica e do ensino superior" (Brasil 2012: 16).

Os estagiários também ressaltam a contribuição do Estágio Supervisionado I para uma melhor visão sobre as dificuldades em ensinar física no Ensino Fundamental (cerca de 20\%). Como exemplo podemos citar à afirmação de um participante do $6^{\circ}$ Período: "O fato dele ser desenvolvido no ensino fundamental, reforça a importância de se estudar física nesse nível de ensino, promovendo desde cedo a educação científica." Nesta etapa, o objeto de estudo da ciência, em particular da Física, é o mundo próximo do estudante, o qual já possui alguma concepção referente ao seu funcionamento que difere do ponto de vista científico, e que muitas vezes acaba por dificultar a aprendizagem desses estudantes. Pozo \& Crespo (2009: 193) ressalta que "no final do ensino fundamental e no primeiro ano do ensino médio as principais dificuldades do aluno estarão determinadas pela forma como ele vê o mundo", assim, percebe-se a importância de se investigar sobre asdificuldades nesse nível, considerando a importância do Ensino da Física para a construção de uma visão de mundo na perspectiva científica por parte dos estudantes, bem como para se ter uma postura diferente nos anos seguintes a essa etapa educacional.

Portanto, fica evidente a importância do Estágio Supervisionado I ser desenvolvido ainda no Ensino Fundamental, contribuindo e possibilitando uma ação futura consciente das dificuldades que os estudantes podem apresentar em aprender Física no ensino médio, na perspectiva de superá-las em atividades futuras (Carvalho 2013). Os estudantes ressaltaram também, em meio a essas dificuldades em ensinar Física no Ensino Fundamental, a precariedade das escolas, a indisciplina e a falta de interesse dos estudantes. Essas dificuldades remetem à realidade atual da educação brasileira no âmbito do ensino básico, e neste cenário a formação docente qualificada e preparada pode possibilitar mudanças significativas (Celestino 2016).

Em menor percentual aparece o ponto "requisito para a conclusão do curso" (cerca de $4 \%$ ), revelando de certo modo, sem generalizações, uma ideia singela de que o Estágio Supervisionado I é meramente uma parte burocrática, sem muitas contribuições para o desenvolvimento intelectual dos estagiários ao longo do curso, desprovida "de uma meta investigativa e reflexiva" (Barreiro \& Gebran 2016: 26). Para tanto, devemos atribuir significado ao Estágio Supervisionado I, considerando-o como "um lugar por excelência para que o futuro professor faça a reflexão sobre sua formação e sua ação, e dessa forma possa aprofundar conhecimentos e compreender o seu verdadeiro papel e o papel da escola na sociedade." (Barreiro \& Gebran 2016: 90).

A questão 3 visa identificar quais as dificuldades e as facilidades que os estagiários encontraram ao cumprir o período de regência do Estágio Supervisionado I, considerando tudo aquilo que os mesmos estudaram na teoria, buscando assim, investigar se de fato "na prática a teoria é outra". Isto evidencia o distanciamento que pode existir entre os fundamentos teóricos estudados no curso com a realidade da prática em sala de aula. Ilustramos a seguir os pontos colocados como facilidades encontradas pelos estagiários durante o estágio de regência (Figura 3) e os pontos colocados como dificuldades (Figura 4).

Observa-se que uma grande parte dos estagiários não destacou ter encontrado facilidades nessa etapa de regência em sala de aula $(40 \%)$. A exemplo, podemos citar a afirmação de um dos participantes do $8^{\circ}$ período ao mencionar que "As facilidades não existem, trabalhar com educação nunca será um processo fácil.” Isto está de acordo com o que afirma Celestino:

Pensar a sala de aula, seu cotidiano não é algo fácil, tendo em vista a complexidade dos sujeitos, sua singularidade, seu ser. Olhar para essa realidade é visualizar os sujeitos a constantes trocas simbólicas, as quais modificam vidas, ampliam sonhos, possibilitam conquistas (Celestino 2016: 96). 


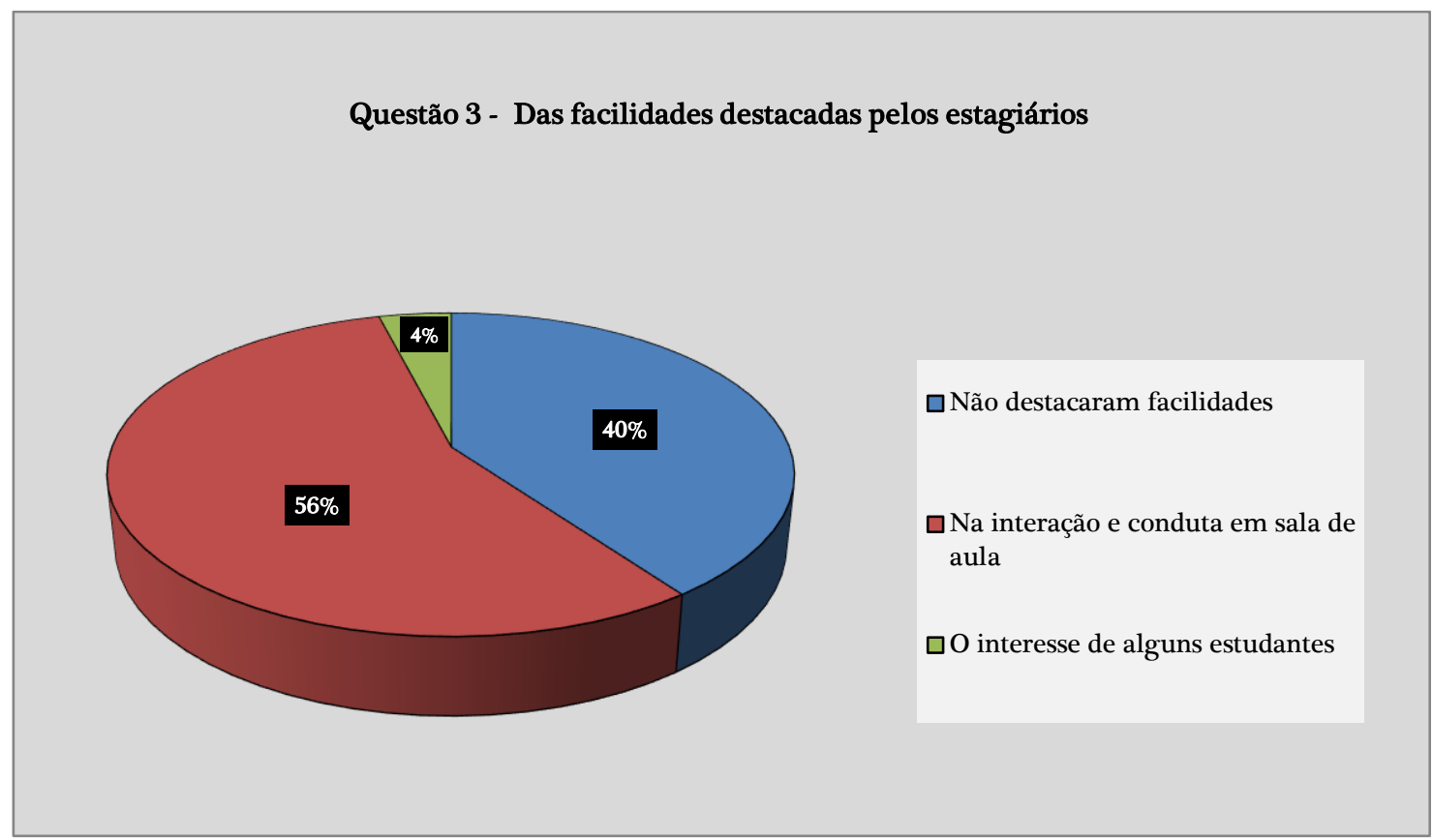

Figura 3. Facilidades destacadas pelos estagiários durante o estágio de regência considerando os fundamentos teóricos estudados no curso.

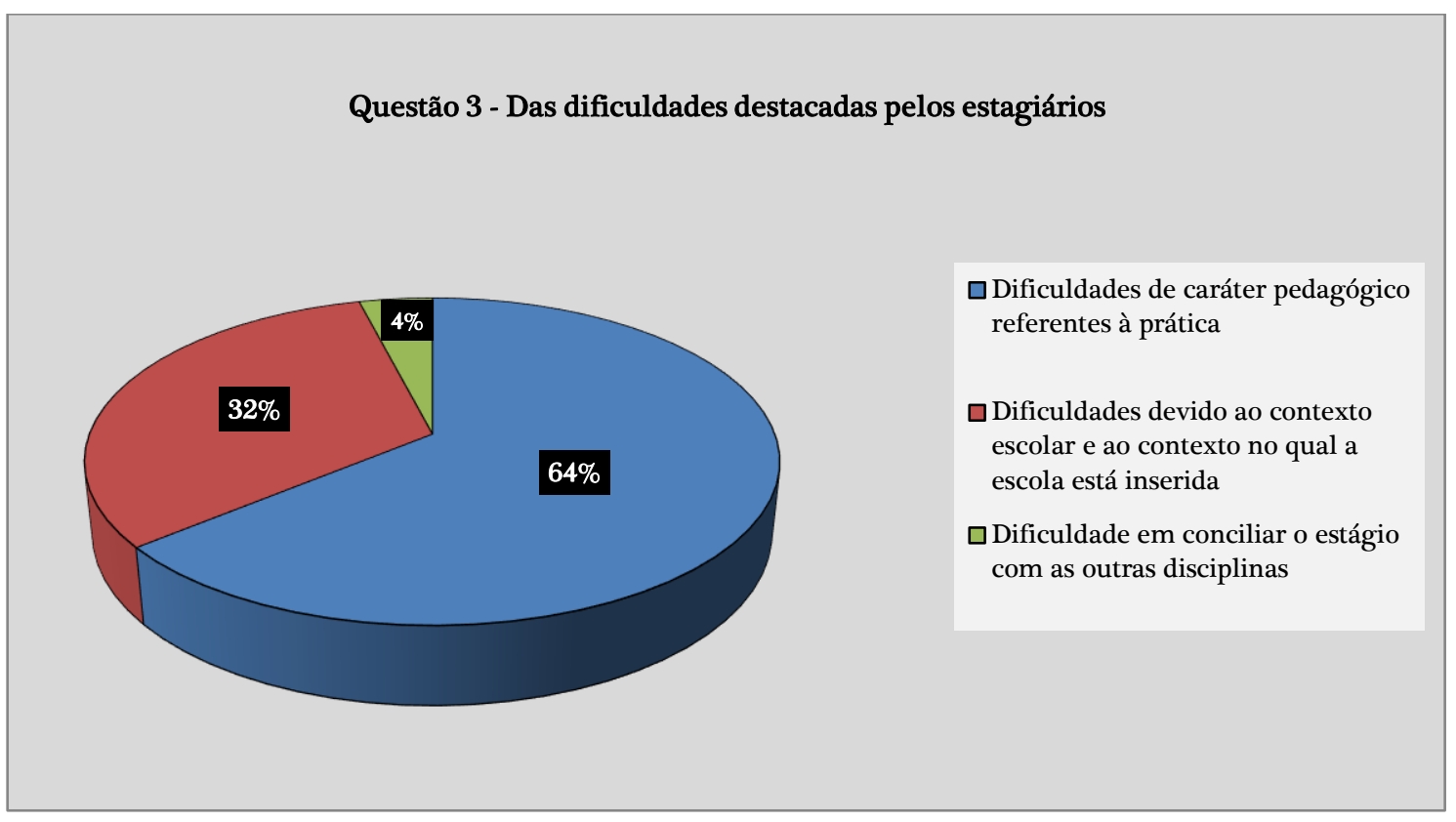

Figura 4. Dificuldades destacadas pelos estagiários durante o estágio de regência considerando os fundamentos teóricos estudados no curso.

$\mathrm{O}$ ponto que aparece em destaque $(56 \%)$ revela as facilidades quanto à postura e a conduta dos estagiários em sala de aula e no ambiente escolar, como é mencionado pelos mesmos:

“A relação com o professor supervisor e com a turma, facilitou $o$ desenvolvimento das atividades do estágio de regência." (estudante do $6^{\circ}$ período)

[...] facilidade na interação com a turma, as disciplinas práticas ajudaram nesta parte." (estudante do $8^{\circ}$ período) 
[...] como já trabalhava como professor todas as dificuldades são interpretadas e encaradas com mais naturalidade; facilidade de dialogar e conduzir a aula." (estudante do $7^{\circ}$ período)

Essas facilidades foram destacadas por quase todos os estagiários que já trabalharam ou possuíam alguma experiência como docentes. Assim, por não ser o primeiro contato destes com uma sala de aula, eles não tiveram tanta dificuldade em relação à interação e conduta, bem como no planejamento. O outro ponto em menor percentual (4\%) está relacionado ao interesse de alguns estudantes, não de todos, em querer aprender.

Quanto às dificuldades, os estagiários destacaram tanto dificuldades impostas pelo contexto escolar e pelo contexto no qual ela está inserida (32\%) como também as dificuldades de caráter pedagógico referentes à prática $(64 \%)$, no sentido de planejamento e desenvolvimento atividades de ensino diferentes das realizadas tradicionalmente:

[....] na realidade enfrentamos diversas dificuldades, tanto por parte dos sujeitos envolvidas quanto pela própria estrutura física da escola; que na maioria das vezes é precária." (estudante do $6^{\circ}$ período)

"Os movimentos na escola interferem muito no desenvolvimento das atividades, por exemplo, não ter aula, isso ou aquilo."(estudante do $8^{\circ}$ período)

“....] dentre as dificuldades podemos elencar a falta de materiais didáticos (laboratórios e/ou similares) na escola, o desinteresse dos alunos pela disciplina, e o grau de abstração dos conteúdos."(estudante do $7^{\circ}$ período)

“[...] muitas vezes os estudantes da educação básica resistiam na realização das atividades." (estudante do $8^{\circ}$ período)

"Minhas maiores dificuldades foram a questão da transposição didática em aulas interdisciplinares." (estudante do $6^{\circ}$ período)

"As discussôes teóricas nem sempre se alinham a realidade vivenciada na escola, neste espaço, a dinâmica observada apresenta muitas variáveis que podem, por um lado, contribuir e do outro prejudicar a prática pedagógica." (estudante do $10^{\circ}$ período)

"A maior dificuldade é em pôr em prática tudo que estudei na teoria, [...] não há facilidades neste processo." (estudante do $7^{\circ}$ período)

Para Martins (2009: 4) "é natural que professores em início de carreira tenham, em geral, muitas dificuldades em lidar com os alunos, no sentido do estabelecimento de um ambiente propício à aprendizagem.” Essas dificuldades enfrentadas de caráter pedagógico no desenvolvimento da prática revelam um ponto a ser discutido no âmbito do curso, no sentido de desenvolvimento de práticas que permitam a produção de problemas que remetem a essa realidade de modo significativo. Desse modo, percebe-se o quanto é importante que as disciplinas que antecedem essa etapa busquem "permitir vivências que não se limitem a um reforço de práticas tradicionais.” (Martins 2009: 6).

O ponto que aparece em menor percentual (4\%), em especial, demonstra uma dificuldade particular em relação à grande demanda das atividades exigidas no estágio, já que $o$ estudante tem que cursar outras disciplinas do curso no mesmo período letivo, devido à distribuição da carga horária e das disciplinas do curso. $\mathrm{O}$ discente sente dificuldade pelo descompasso gerado entre os "hábitos, calendário e demais atividades e rotinas da universidade e da escola" (Pimenta \& Lima 2012: 104). Por ser um pequeno percentual não podemos fazer generalizações, porém, é algo a se considerar.

Portanto, considerando ainda os dados obtidos na questão 3, percebe-se que para aqueles estagiários que nunca tiveram a experiência como docente em sala de aula, os desafios enfrentados são muitos. Parece-nos que os conteúdos estudados por eles teoricamente, até então, pouco têm contribuído para essa etapa, no que diz respeito na elaboração das atividades de ensino e em como lidar com as adversidades que possam surgir na prática em sala de aula. É claro que o impacto é muito grande, "não é difícil, por exemplo, imaginar a intensa atividade cognitiva e a forte carga emocional, envolvidas no primeiro contato do futuro professor" ou do professor que já leciona "com alunos de uma turma, que nunca, até aquele momento do estágio supervisionado, estiveram sob sua "total” responsabilidade.” (Brasil 2012: 15). Para Pimenta \& 
Lima (2012) a dissociação entre teoria e prática na formação docente resulta em um empobrecimento das práticas na escola, evidenciando desde modo, a necessidade que temos em considerarmos o "estágio teórico e prático (e não teoria ou prática).”

$\mathrm{Na}$ questão 4 os estudantes foram indagados sobre a Importância do Estágio Supervisionado I para a Formação Docente. Os dados obtidos estão expostos na Figura 5. Percebe-se que as considerações em relação à importância do Estágio Supervisionado I para a formação como docente, na perspectiva dos estagiários, estão concentradas na possibilidade de vivência e compreensão do ambiente escolar e de sala de aula (60\%) para uma melhor prática durante a profissão de magistério, como também em relação à identificação como docente (28\%) e na construção da própria prática pedagógica (12\%).

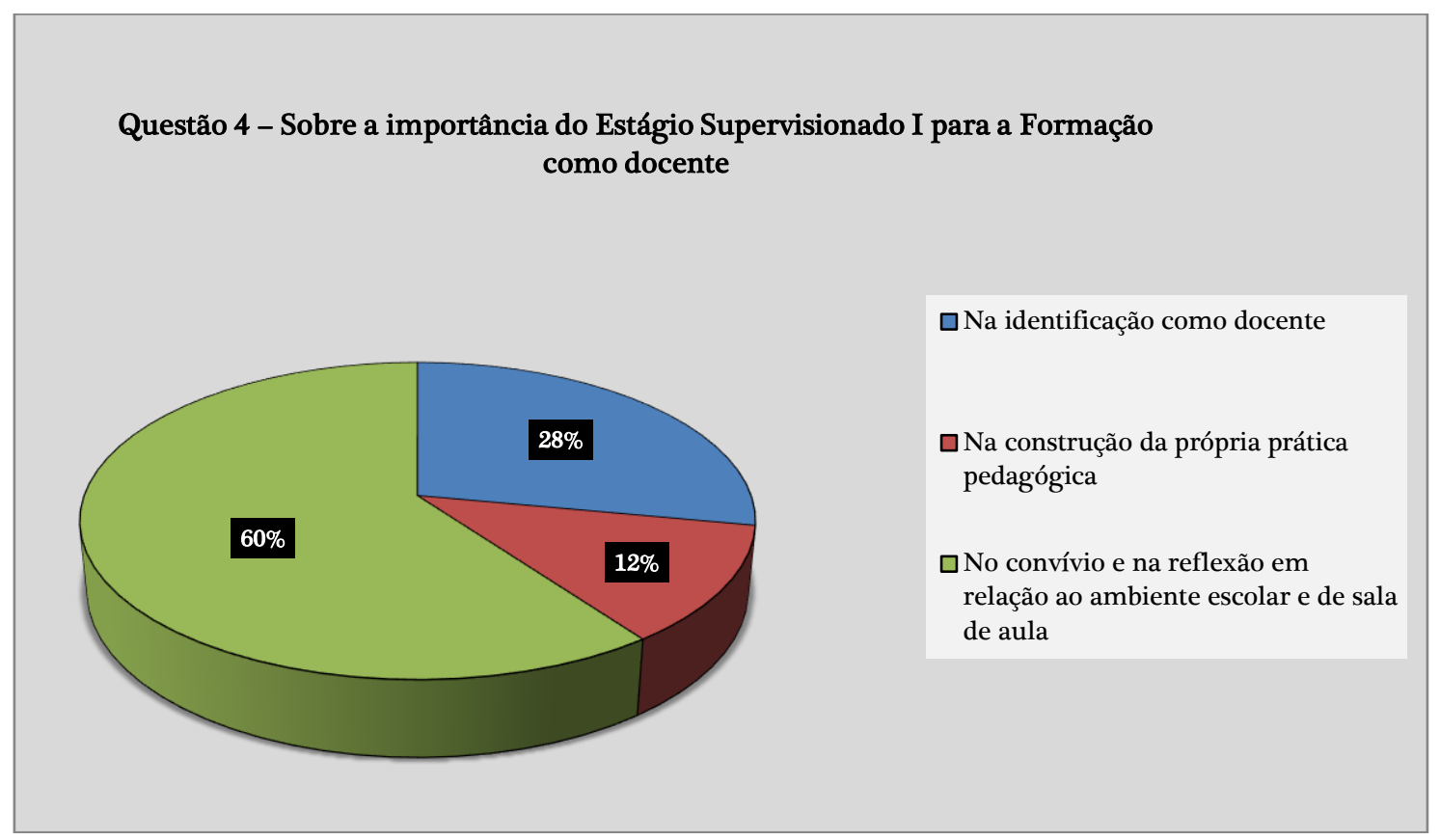

Figura 5. Da Importância do estágio supervisionado para a Formação como docente na perspectiva dos estagiários.

Observamos, portanto, que a opinião da maioria dos estagiários vai contra o reconhecimento de que o estágio deve ser "mais do que um componente obrigatório nos currículos de formação de professores, é um daqueles momentos especiais da formação da identidade profissional do professor de física” (Brasil 2012: 15). Isto é um ponto negativo, pois, adicionalmente, como coloca Pimenta \& Lima (2012), o estágio deve se caracterizar também como um lugar de reflexão para a construção e o fortalecimento da identidade profissional docente.

Finalmente, na questão 5, fizemos um esboço geral em relação ao Estágio Supervisionado I, identificando e explicitando as considerações gerais dos estagiários, sendo os mesmos indagados tanto em relação aos contentamentos quanto às contestações em que possam ter referente às experiências vividas no Estágio I. O participante tinha total liberdade para apresentar as suas considerações. Estas considerações gerais dos 25 estagiários foram categorizadas, uma vez que se assemelhavam no sentido de terem a mesma ideia, sendo estas concentradas nos pontos apresentados na Tabela 1.

De modo geral, podemos dizer que os estagiários consideraram ter sido uma boa experiência, “apesar do grande desgaste emocional, físico e intelectual” (frase afirmada por um participante da pesquisa do $8^{\circ}$ período). Vale ressaltar que esse desgaste é algo inerente a profissão docente, como de qualquer outra profissão, e que neste sentido é importante que o discente o vivencie, pois poderá optar por continuar ou não na profissão docente. Percebe-se, pelos pontos destacados na Tabela 1 que as considerações gerais dos estagiários referentes ao Estágio I remetem principalmente às experiências pessoais vividas nessa etapa, as quais têm contribuído significativamente para sua formação, não só como pessoa, ao interagir com pessoas 
de diferentes contextos, mas também profissional, ao permitir o contato e reflexão dos problemas enfrentados na sala de aula nesse nível de ensino, em particular sobre o ensino de Ciências. Podemos dar ênfase ao ponto que coloca em questão o fato de não haver uma reflexão na universidade em relação às atividades desenvolvidas nessa etapa pelos estagiários, que podem "trazer contribuições não só para a profissionalização do professor, mas também para a formação dos alunos no ensino básico” (Silva \& Fajardo-Turbin 2012: 25).

Tabela 1. Considerações gerais dos estagiários em relação ao Estágio Supervisionado I.

\section{Considerações gerais dos estagiários}

\begin{tabular}{clc} 
& & $\%$ \\
\hline $\mathbf{1}^{\mathbf{0}}$ & Ter contribuído para formação como pessoa e profissional da educação. & $20 \%$ \\
\hline $\mathbf{2}^{\mathbf{0}}$ & $\begin{array}{l}\text { Preparado para o exercício da profissão, uma vez que podemos identificar problemas } \\
\text { e propor soluções para estes problemas. }\end{array}$ & $20 \%$ \\
\hline $\mathbf{3}^{\mathbf{0}}$ & Foi um momento de reflexão se o futuro professor busca uma sala de aula. & $16 \%$ \\
\hline $\mathbf{4}^{\mathbf{0}}$ & Deveria haver uma reflexão das atividades desenvolvidas nessa etapa & $12 \%$ \\
\hline $\mathbf{5}^{\mathbf{0}}$ & Permitiu o primeiro contato dos estudantes com a realidade escolar. & $12 \%$ \\
\hline $\mathbf{6}^{\mathbf{0}}$ & $\begin{array}{l}\text { Reforçou a importância de se estudar física nesse nível de ensino, promovendo desde } \\
\text { cedo à educação científica. }\end{array}$ & $\mathbf{8 \%}$ \\
\hline $\mathbf{7}^{\mathbf{0}}$ & $\begin{array}{l}\text { Permitiu uma visão mais ampla sobre educação e o processo de ensino- } \\
\text { aprendizagem. }\end{array}$ & $\mathbf{8 \%}$ \\
\hline $\mathbf{8}^{\mathbf{0}}$ & As orientações do professor orientador passaram muita segurança. & $4 \%$ \\
\hline
\end{tabular}

\section{Conclusão}

Quando compreendemos a importância do estágio supervisionado, no seu sentido mais amplo, percebe o quão crucial se torna essa etapa para os cursos de Licenciatura em Física. É possível extrair desta etapa saberes prodigiosos que são indispensáveis para a formação profissional docente. Saberes estes que estão intimamente relacionados às experiências vividas e compartilhadas no futuro campo de atuação profissional, ou seja, na realidade escolar. Neste sentido, o estágio deixa de ser compreendido somente como um momento de inserção do estagiário na realidade que possivelmente irá atuar, mas sim como um lugar por excelência para se desenvolver uma postura e uma conduta profissional, consciente e reflexiva no sentido de transformação dessa realidade.

O Estágio Supervisionado I possibilita, além do primeiro contato (se mostrando como um momento de investigação e de aprendizagem com relação à complexidade da prática docente e da realidade escolar), uma reflexão sobre a situação atual do Ensino de Física nas escolas do ensino fundamental, já que o mesmo é desenvolvido nesse nível de ensino. Evidentemente, as questões envolvidas no exercício da profissão docente excedem o curto período de estágio. Entretanto, nessa etapa pode se compreender de forma coerente e significativa as diversas questões que estão envolvidas no contexto dinâmico e complexo que coexiste dentro de uma sala de aula nas escolas do ensino fundamental.

Conscientes dessa perspectiva, esse trabalho permitiu construir uma visão sobre a perspectiva dos estagiários em relação às contribuições do Estágio Supervisionado I para a formação docente no âmbito do curso de Física. A partir dos dados apresentados foi possível perceber com clareza os principais desafios, as principais críticas, e as considerações dos estagiários em relação a essa etapa em especial. Este êxito advém, dentre outras coisas, pela utilização do método de Bardin (1977, 2011), o qual contribuiu no sentido de nortear a análise dos dados em etapas sequenciais bem definidas.

Enquanto aos empecilhos burocráticos, observamos que os estagiários apresentam queixas diversas, que vão desdea elaboração da documentação inicial até a anuência da escola pretendida. Devemos compreender que esta etapa é inerente ao processo e não pode ser ignorada. No entanto, como sugerem os participantes, pode haver uma diminuição da burocracia envolvida, facilitando o processo.

No que diz respeito à contribuição do estágio para a formação do estagiário, podemos destacar o apontamento da maioria dos sujeitos em relação ao fato de que houve melhoria em 
relação às produções acadêmicas de caráter pedagógico do curso. Isto é coerente com o que traz a literatura discutida anteriormente, onde o estágio não deve ser enxergado apenas como a "hora da prática”, mas também como uma oportunidade de dar significado aos conteúdos teóricos aprendidos no curso.

Também devemos evidenciar o fato de que apenas uma parcela minoritária dos estudantes, de acordo com a pesquisa, reconhece o estágio como um meio de identificação como docente, bem como na construção da sua própria prática pedagógica. Isto corrobora as teses iniciais discutidas, onde mostra-se uma carência do estagiário em desenvolver uma prática docente que o promova a um profissional reflexivo.

Destarte, percebe-se também a necessidade inerente no âmbito do curso de Física em se buscar discutir e refletir nas disciplinas que antecedem a etapa do estágio sobre a realidade no qual os discentes irão se deparar. Isto permitirá desenvolver vivências que possibilitem uma articulação de modo significativo entre o que é discutido teoricamente sobre o Ensino de Física e a realidade de sala de aula, como também "vivências que não se limitem a um reforço de práticas tradicionais" (Martins 2009). Para tanto, podemos reforçar a ideia de se considerar as atividades e os trabalhos desenvolvidos pelos estagiários, já que os mesmos se apresentam como fontes potenciais para a construção de saberes significativos referente à prática docente nas escolas, e que podem, assim, contribuir para a formação docente e para a formação dos estudantes da Educação Básica.

\section{Agradecimentos}

Agradecemos ao Programa Institucional de Bolsas de Iniciação à Docência (PIBID) da Coordenação de Aperfeiçoamento de Pessoal de Nível Superior (CAPES) pelo suporte fornecido. Agradecemos também aos revisores deste manuscrito pelas valiosas contribuições.

\section{Referências}

Agrello D.A. \& Garg R. (2009) Mulheres na física: poder e preconceito nos países em desenvolvimento. Revista Brasileira de Ensino de Física, 31(1): 1305-1-1305-6. https://doi.org/10.1590/S1806-11172009000100005

Bardin L. (1977) L'Analyse de Contenu. Paris: Pressesuniversitaires de France. 233 p.

Bardin L. (2011) Análise de Conteúdo. São Paulo: Edições 70. 280 p.

Barreiro I.M.F. \& Gebran R.A. (2016) Prática de Ensino e Estágio Supervisionado na Formação de Professores. $2^{\circ}$ edição. São Paulo: Avercamp. 160 p.

Brasil (2012) Ministério da Educação. Coordenação de Aperfeiçoamento de Pessoal de Nível Superior. Universidade Federal de Goiás. Licenciatura em Física: estágio supervisionado em física - considerações preliminares / Geonovese L.G.R. \& Geonovese C.L.C.R. Goiânia: UFGFUNEPE. $207 \mathrm{p}$.

Carvalho M.A.O. (2009) Estágio Supervisionado na Licenciatura em Física da Uel: Reflexões Sobre a Orientação e a Supervisão. Anais do Congresso Nacional de Educação, 1: 1-14. Curitiba: Editora Champagnat.

Carvalho A.M.P. (2013) Os estágios nos cursos de licenciatura. São Paulo: Cengage Learning. 192 p.

Celestino J.R. (2016) Uma Reflexão Acerca da Formação de Professores e a Realidade Educacional na Contemporaneidade. Revista Científica Multidisciplinar Núcleo do Conhecimento, 9: 85-98.

Coutinho R.X., Folmer V. \& Puntel R.L. (2014) Aproximando universidade e escola por meio do uso da produção acadêmica na sala de aula. Ciência \& Educação, 20: 765-783. http://dx.doi.org/10.1590/1516-73132014000300016

Duarte J.B.A. (2005) Contestação escondida: As críticas de jovens à escola atual. São Paulo: Cortez. $128 \mathrm{p}$.

Leta J. (2003) As mulheres na ciência brasileira: crescimento, contrastes e um perfil de sucesso. Estudos Avançados, 17(49): 271-284. https://doi.org/10.1590/S0103-40142003000300016

Marconi M.A. \& Lakatos E.M. (2017) Técnicas de Pesquisa. $8^{\circ}$ edição. São Paulo: Atlas. 318 p. 
Martins A.F.P. (2009) Estágio supervisionado em Física: o pulso ainda pulsa.... Revista Brasileira de Ensino de Física, 31(3): 3402-1-3402-7.

Minayo M.C.S. \& Sanches O. (1993) Quantitativo-Qualitativo: Oposição ou Complementaridade? Cadernos de Saúde Pública, 9(3): 239-262. https://doi.org/10.1590/S0102-311X1993000300002

Pimenta S.G. (2013) O estágio na formação de professores: unidade, teoria e prática? $11^{\circ}$ edição. São Paulo: Cortez. 224 p.

Pimenta S.G. \& Lima M.S.L. (2012) Estágio e docência. $7^{\circ}$ edição. São Paulo: Cortez. 312 p.

Pozo J.I. \& Crespo M.A.G. (2009) A aprendizagem e o ensino de ciências: do conhecimento cotidiano ao conhecimento científico. $5^{\circ}$ edição. Porto Alegre: Artmed. 296 p.

Prodanov C.C. \& Freitas E.C. (2013) Metodologia do trabalho científico: métodos e técnicas da pesquisa e do trabalho acadêmico. $2^{\circ}$ edição. Novo Hamburgo: Feevale. 276 p.

Silva W.R. \& Fajardo-Turbin A.E. (2012) Como fazer relatórios de estágio supervisionado: formação de professores nas licenciaturas. Volume 1. Brasília: Liber Livro Editora. 232 p.

Silva L.C. \& Miranda M.I. (2008) Estágio Supervisionado e Prática de Ensino: Desafios e Possibilidades. $1^{\circ}$ edição. Volume 1. Araraquara: Junqueira \& Marin editores. 178 p. 